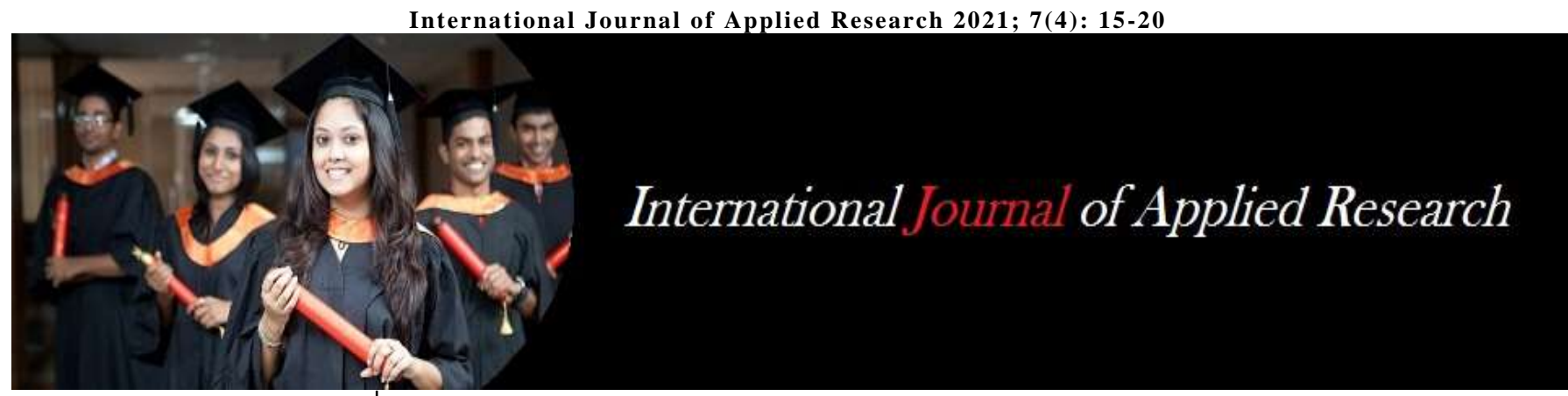

ISSN Print: 2394-7500 ISSN Online: 2394-5869 Impact Factor: 8.4 IJAR 2021; 7(4): 15-20 www.allresearchjournal.com Received: 09-02-2021 Accepted: 19-03-2021

Sangeeta Lakra Govt. College of Nursing, Ambikapur, Surguja, Chhattisgarh, India
Corresponding Author: Sangeeta Lakra Govt. College of Nursing, Ambikapur, Surguja, Chhattisgarh, India

\section{A comparative study to assess the effectiveness of warm compress vs magnesium sulphate application on superficial thrombophlebitis among patients admitted in a selected hospital at Ambikapur, Chhattisgarh}

\section{Sangeeta Lakra}

DOI: https://doi.org/10.22271/allresearch.2021.v7.i4a.8454

\begin{abstract}
Introduction: The history of intravenous therapy began with the discovery by Sir. Williams Harvey. The first practical application was by Dr. Thomas Latta, who used infusion of saline to treat the intractable diarrhea. Approximately $90 \%$ of patients in acute care setting receive some form of intravenous infusion therapy. Over one fourth of hospitalized patients receive intravenous therapy for fluid replacement and administration of drugs. It is also recognized that intravenous therapy exposes the patient to a considerable variety of hazards and less commonly to grave danger. The incidence of superficial thrombophlebitis is related to with the length of time, I.V. line in place, composition of fluid or medication infused, size of the cannula and the site of insertion, improper anchoring of the line and the introduction of microorganisms at the time of insertion.

Methods research approach: Pre-experimental research design (one group pretest-postest design) was used Here in this study two groups were taken and observed after the independent variable were introduced (application of warm compress and magnesium sulphate on superficial thrombophlebitis). The setting for this study was the selected area of hospital at Ambikapur, Chhattishgarh. Sample were selected by using purposive sampling technique and then assigned into two groups; Group -A and group-B. The Pre-test was taken using a semi structured superficial thrombophlebitis scale, selected socio-demographic and clinical variables. Following the pre- test interventions were carried out for both groups. Warm compress application was given to group-A for 20 minutes and magnesium sulphate application was given to group-B by dipping the gauze in the solution and applied on superficial thrombophlebitis, which was applied till next dressing change. Study comprised of 60 patients (Group A-30 Patient \& Group B-30 patient) with superficial thrombophlebitis. Semistructured questionnaire was used for collecting the data. It consists of tools.
\end{abstract}

Section A: Selected Socio-demographic profile

Section B: Selected clinical variables profile

Section C: Semi- structured superficial Thrombophlebitis scale

Semi-structured superficial thrombophlebitis scale, selected socio-demographic and clinical questions were submitted to seven experts in the field of medical surgical nursing, expert were selected on the basis of their clinical expertise, experience and interest in the problem being selected. Tool validity was done and tool found reliable. The reliability coefficient was calculated by using karl Pearson formula to determine reliability coefficient. The value of ' $r$ ' was found 0.98 , hence the tool was reliable. Study found feasible after pilot study.

Result: Sample characteristic were analysed by using frequency and percentage. Mean, mean difference and standard deviation and ' $t$ ' test were done for analysing the effectiveness of warm compression and magnesium sulphate application on superficial thrombophlebitis. Chi-square test was computed to determine the association between the selected clinical variables in both group. The comparison between warm compress application and magnesium sulphate application was found by using paired ' $t$ ' test which showed The calculated ' $t$ ' value 22.22 and 8.9 respectively is greater than table value $\left(t_{59}=2.00\right)$. Mean difference of pre-test and post-test score of Group A (1.8) is greater than mean difference of pre-test post- test - score of group-B(1). This shows that there is significant difference between warm compress and magnesium sulphate application in reducing the superficial thrombophlebitis at 0.05 level of significance.

Conclusion: Significant reduction in superficial thrombophlebitis with warm compress application and magnesium sulphate application, which shows that both interventions are effective in reducing the signs 
and symptoms of superficial thrombophlebitis. Significant difference between the effect of warm compress and magnesium sulphate application, which shows that warm compress application is more effective than magnesium sulphate application on superficial thrombophlebitis.

Keywords: Effective, superficial thrombophlebitis, warm compress and magnesium sulphate

\section{Introduction}

A common problem encountered during IV therapy is the superficial thrombophlebitis, i.e. the inflammation of the venous wall near the point of entry of the cannula into the veins. It is often due to patient movement and disruption of vein at the site of insertion of the cannula. The patients who are on cytotoxic drugs, hyper-osmolar agents and vasoactive drugs are more prone to phlebitis. Phlebitis means inflammation of a vein. Thrombosis or thrombophlebitis of the superficial venous system receives little attention in textbooks of surgery and medicine. However, thrombophlebitis is encountered frequently and, at times, can cause significant incapacitation. Therefore, nurses are in a pivotal position to manage infiltration through effective nurse-initiated intervention that are economical in both nursing times and resources. In the past, drugs have been the conventional methods to alleviate pain and swelling, but in many instances, medications themselves do not provide optimal results.

\section{Objectives}

1. To Assess the Superficial Thrombophlebitis before and after the Administration of Warm Compress among Patients Admitted in a Selected Hospital.

2. To Assess the Superficial Thrombophlebitis before and After the Administration of Magnesium Sulphate.

3. To Compare the Effectiveness of Warm Compress and Magnesium -Sulphate Application on Superficial Thrombophlebitis.

4. To Find the Association with pre-test superficial thrombophlebitiss score and selected demographic variables in Group-A and Group-B.

5. To Find the Association with pre-test superficial thrombophlebitis score and selected clinical variables in group-A and Group-B.

\section{Research design}

Pre-experimental research design (one group pretest-postest design) was used.

\section{Research Setting}

The study was conducted in medical, surgical wards and intensive care unit of Holy Cross Hospital, Ambikapur, Chhattisgarh.

\section{Population}

Population for the study were patients admitted in hospital with superficial thrombophlebitis.

\section{Sample}

The sample for this study comprised of 60 patients with superficial thrombophlebitis.

\section{Sampling Technique}

The samples were selected through a purposive sampling.

\section{Sampling Criteria for selection of Sample \\ Inclusion criteria}

1. With superficial thrombophlebitis related to IV cannulization.

2. Willing to participate in the study and who are admitted during the data collection period.

3. Between 18 years and above 50 years of ageOn IV fluid therapy irrespective of whether medicated or nonmedicated.

4. Conscious patient and does not suffer from any skin disorders.

5. With mild and moderate superficial thrombophlebitis in the fore arm.

\section{Exclusion Criteria}

1. Not willing to participate in the study.

2. Absent at the time of date collection

3. Severe type of superficial thrombophlebitis.

\section{Data collection instrument}

Tools consists of

Section A: Selected Socio-demographic profile

Section B: Selected clinical variables profile

Section C: Semi- structured superficial thrombophlebitis scale.

\section{Description of the tool}

\section{Section A: Selected Socio-demographic data}

This section consists of three items regarding age, sex and history of previous hospitalization which are influencing the superficial thrombophlebitis.

\section{Section B: Selected clinical variables profile}

This section consists of 9 item and they are clinical area, vein used for insertion cannula, size of the I.V. cannula, types of the infusion solutions, total amount of fluid per 24 hrs, duration of the cannula in vein, trial used in inserting cannula, types of I.V. medications and clinical History, these are the factors affecting the superficial thrombophlebitis.

\section{Section C: Semi- structured superficial thrombophlebitis scale}

A semi-structured superficial thrombophlebitis scale was developed after reviewing the review of literature and after the discussion from the experts to assess the superficial thrombophlebitis. Semi- structured superficial thrombophlebitis scale comprised of 6 items. They are:-

- I.V. site appears healthy

- Pain near the I. Vsite or slight redness near the I.V. site

- Redness around site

- Swelling

- Pain along path of cannula

- Palpable venous cord

\section{Pilot Stduy}

Pilot study was conducted at Holy Cross Hospital, Kanuri C.G. from 8-12-12 to 14-12-13.10.Patients were selected by using purposive sampling technique and then assigned into two groups; Group -A and group-B. The Pre -test was taken using a semi structured superficial thrombophlebitis scale, selected socio-demographic and clinical variables. Following the pre- test interventions were carried out for both groups. Warm compress application was given to 
group-A for 20 minutes and magnesium sulphate application was given to group-B by dipping the gauze in the solution and applied on superficial thrombophlebitis, which was applied till next dressing change. Both interventions the warm compress and magnesium sulphate application were given twice in a day (9.30 a.m. and 7 p.m.) for three days. Post- test in the form of observation, using the semistructured superficial thrombophlebitis scale was done. First observation was done after $24 \mathrm{hrs}$. Of interventions, second observation was carried out after $48 \mathrm{hrs}$. And last observation was done after 72 hrs., to evaluate the effectiveness of warm compress and magnesium sulphate application on superficial thrombophlebitis. The study was found feasible and practicable.

\section{Validity}

Semi-structured superficial thrombophlebitis scale, selected socio-demographic and clinical questions were submitted to seven experts in the field of medical surgical nursing, expert were selected on the basis of their clinical expertise, experience and interest in the problem being selected.

\section{Reliability}

The questionnaires were administered to 10 subjects 5 each in Group-I and Group-II. The reliability was established using split- half of Karl Person's coefficient formula. The reliability coefficient was found to be (0.98).Hence, the tool was found to be reliable.

\section{Ethical consideration}

The research committee has approved the research problem and objectives stated for present study. Informed consent was obtained from all the surgical and medical patients who were willing to participate in the study. Explanation was given regarding the purpose of the study. Confidentiality was ensured. Permission obtained from Administrator and Nursing Superintendent to conduct the main study from Holy Cross Hospital Ambikapur (C.G.)

\section{Data Collection Procedure}

Data collection was done from 27.12.12 to 14.01.13 at Holy Cross hospital, Ambikapur. The clients were taken from surgical intensive care unit, surgical -A, maternity - B, Gynaecology-G ward, and medical female -C, Medical intensive care unit, medical male $-\mathrm{E}$ ward who were receiving intermittent I.V. medication. 60 sample were divided into two groups by purposive random sampling and assigned into two groups Group-A and Group-B. The pretest was taken using a semi-structured superficial thrombophlebitis. scale for both groups. Post-test were conducted after the treatment with the help of semistructured superficial thrombophlebitis.

Following the pre- test interventions were carried out for both groups. Warm compress application was given to group-A for 20 minutes and magnesium sulphate application was given to group-B by dipping the gauze in the solution and applied on superficial thrombophlebitis, which was applied till next dressing change. Both interventions the warm compress and magnesium sulphate application were given twice in a day (9.30 a.m. and 7 p.m.) for three days. Post- test in the form of observation, using the semistructured superficial thrombophlebitis scale was done. First observation was done after 24 hrs. Of interventions, second observation was carried out after $48 \mathrm{hrs}$. And last observation was done after 72 hrs., to evaluate the effectiveness of warm compress and magnesium sulphate application on superficial thrombophlebitis.

\section{Analysis and interpretation of data}

In order to find the effectiveness of Warm compress and magnesium sulphate application on superficial thrombophlebitis data were tabulated, analyzed and interpreted using descriptive and inferential statistical method. Data were presented under the following headings.

\section{Major Findings of the Study \\ Section-I \\ Distribution of subjects according to selected Socio- demographic variables and selected clinical variables using frequency and percentage in group- $A$ and group-} B.

Regarding age, among all subjects highest percentage $40 \%$ of the subjects were in the age group of 20-30yrs. The percentage distribution of subjects according to the sex 60 $\%$ of subjects were female. In relation to history of previous hospitalization $63.33 \%$ of subjects had history of previous hospitalization. The finding regarding clinical area, $76.67 \%$ of the subjects were admitted in the medical ward. About vein used for inserting cannula, $50 \%$ of subjects had insertion of cannula in the dorsal vein and radial vein. Out of 60 subjects, $73.67 \%$ of subjects had isotonic solution infusion. Related to the total amount of fluids per $24 \mathrm{hrs}$, $46.67 \%$ of subjects had more than 4 pints of fluids per $24 \mathrm{hrs}$. Finding shows that $80 \%$ of subjects had cannula in vein for 24-48hrs.

Regarding trial used in inserting cannula, 86.67\% subjects had one trial in inserting cannula. Relation to types of I.V. medications, $100 \%$ of subjects received antibiotics. The finding regarding clinical history, $76.67 \%$ of subjects had no clinical history of diabetic, hypertension and peripheral vascular disease.

\section{Section-II}

a. Deals the effectiveness of warm compress and magnesium sulphate application in terms of reducing superficial thrombophlebitis

The finding related to effectiveness of warm compress in reducing the signs and symptoms of superficial thrombophlebitis shows that the calculated ' $t$ ' valve (26.6) is greater than table value $\left(t_{29}\right)=2.05$, this shows the warm compress application is effective in reducing superficial thrombophlebitis at 0.05 level of significance. The finding related to effectiveness of magnesium sulphate application in reducing the signs and symptoms of superficial thrombophlebitis shows that the calculated ' $t$ ' valve (12.5) is greater than table value $\left(\mathrm{t}_{29}\right)=2.05$, this shows the magnesium sulphate application is effective in reducing superficial thrombophlebitis at 0.05 level of significance.

\section{b. Comparison of effectiveness of warm compress application and magnesium sulphate application in terms of reducing superficial thrombophlebitis}

The pre-test mean score of group-A is 2.8, post-test score is 1 , mean difference of pre-test and post- test is 2 with standard deviation 0.52. Pre-test mean score of group-B is 2.8 , post-test score is 1.8 , mean difference of pre-test and post- test is 0.89 with standard deviation 0.10 . Paired t' test computed between scores of group-A and group-B was 
statistically significant at 0.05 level of significance. The calculated ' $t$ ' value 22.22 and 8.9 respectively is greater than table value $\left(\mathrm{t}_{59}=2.00\right)$. Mean difference of pre-test and post-test score of Group A is greater than mean difference of pre-test post- test - score of group-B. Hence hypotheses accepted that there is significant difference between warm compress and magnesium sulphate application in reducing the superficial thrombophlebitis was accepted. The finding shows that warm compress application is more effective in reducing signs and symptoms of superficial thrombophlebitis than magnesium sulphate application.

\section{Section III}

\section{a. Association with pre-test superficial thrombophlebitis score and selected socio- demographic variables in group A and group-B.}

To determine the significant association of pre-test superficial thrombophlebitis score and selected demographic variable chi square was used. There was no significant ( $\mathrm{p}<$ 0.05 level) association with superficial thrombophlebitis and selected demographical variables like age, sex and history of previous hospitalization in group-A and group-B.

\section{b. Association with pre-test superficial thrombophlebitis score and selected clinical variables in group $-\mathbf{A}$ and group-B}

There was a significant ( $\mathrm{p}<0.05$ level) association with pretest superficial thrombophlebitis score and selected clinical variables in group-A, Such as clinical area (chi-square value $=20.78$, df 2 , at $\mathrm{p}=0.05$ ). Whereas there was no significant association between the other selected clinical variables such as clinical area, vein used for insertion cannula, size of the I.V. cannula, types of the infusion solutions, total amount of fluid per $24 \mathrm{hrs}$., duration of the cannula in vein, trial used in inserting cannula, types of I.V. medications and clinical History. There was a significant $(0<0.05$ level $)$ association with pre-test superficial thrombophlebitis score and selected clinical variables in group-B, Such as clinical area (chi-square value $=5.31$, df 2 , at $\mathrm{p}=0.05$ ). Whereas there was no significant association between the other selected clinical variables such as clinical area, vein used for insertion cannula, size of the I.V. cannula, types of the infusion solutions, total amount of fluid per $24 \mathrm{hrs}$., duration of the cannula in vein, trial used in inserting cannula, types of I.V. medications and clinical History.

\section{Conclusion}

The following conclusion was drawn based on the findings of the study.

1. There is a significant reduction in superficial thrombophlebitis with warm compress application and magnesium sulphate application, which shows that both interventions are effective in reducing the signs and symptoms of superficial thrombophlebitis.

2. There is a significant difference between the effect of warm compress and magnesium sulphate application, which shows that warm compress application is more effective than magnesium sulphate application on superficial thrombophlebitis.

3. There is an association with pre-test superficial thrombophlebitis score and selected clinical variables such as clinical areain both group -A and group- B.

\section{Implication}

The present study was conducted to find the effectiveness of warm compress application and magnesium sulphate application on superficial thrombophlebitis patients admitted in the hospital. Several implication for nursing practice, education, administration and research can be stated on the findings of this study.

\section{Limitation}

The limitation of the present study are as follows

- This study is limited to 60 surgical and medical patients admitted in the hospital.

- Patients who are admitted in medical and surgical wards and receiving intravenous medication.

- Unplanned discharged patients were hindrance to their participation in study.

\section{Recommendations}

On the basis of findings of the study following recommendations have been made for further study:

- A similar study can be conducted in different hospital with large sample size.

- A study can be conducted with demographic variables and factors influencing the superficial thrombophlebitis.

- Replication of study on a large sample may help to draw more definite conclusions and make generalization.

\section{Acknowledgement}

The investigator express immense gratitude to the Lord Almighty for his omnipresence throughout this endevour.

It is my pleasure and privilege to express my deep sense of gratitude and thanks to all those who have contributed to the successful completion of this endeavor.

I express my heartful gratitude and sincere thanks to prof. Sr. Philomena toppo, Vice principal, Holy Cross college of nursing, Ambikapur, who guided me as a co-guide and rendered her special research skill, expert guidance, constant support, encouragement and valuble suggestions for the successful completion of this work.

I express my heartfelt thanks to Prof. Sr. Caroline, principal, Holy Cross College of nursing, Ambikapur, for her efficient guidance, untiring and patient correction, encouragement and valuable suggestions which helped me to lay stronge foundation of this study. Indeed I was highly blessed to have such great personality as my research guide.

I sincerely gives to my research team for the encouragement and guidance given by them.

I express my deepest gratitude and thanks to Miss Mukti Rose Ekka and Mr. Laiju Joy (MSc. Nursing) Medical Surgical department, Lecturer, Holy Cross College of Nursing Ambikapur, for their constant support, valuable guidance and moral support at every storage of the study which helped me in giving shape to this study.

I extend my sincere thanks to Dr. Garg, statistician, for guidance and critical statistical advice.

The study would not have been possible without the constant encouragement, inspiration and valuable support of all teching faculty of Holy Cross College of nursing. So I all heartedly express my sicere thanks to Sr.Consolata MSc (N), Professor Nursing Education, Sr. Sarla Ekka MSc.(N) Senior Lecturer, MS Veenita Kachap MSc.(N), Obsterical 
Gynaecology department, lecturer, Sr. Jenifer Desouza MSc.(N) paedrics, lecturer, Mrs. Shradha Asawan MSc.(N) Community Health Nursing, lecturer, Ms. Anubhuti MSc.(N) Community Health Nursing, lecturer, Mr. Ajay M.Sc.(N), Mental health nursing Department.

I remain ever indebted to the experts who contributed their valuable time and efforts in validating the tool and their appropriate suggestion.

My thanks to Mrs. Philis Toppo and Mrs. Nirjhar Toopo Labrarian Holy Cross College of Nursing Ambikapur for their corperation and pryers, for completing of my study.

My heartfelt thanks to all sisters of Holy Cross Convent for their constant pryers, encouragement, trust and support during the period of study.

My sincere thanks to all Nursing staff of Holy Cross Hospital Ambikapur for their co-operation during the data collection.

I am highly indebed and express my deep sense of gratitude to my father Mr. Louis Lakra, Mother Mrs Mary Stella lakra. Sisters Leema and Manju Lakra and Dilip Lakra for their perpetual love, care, prayers and their support in the achievement of my goal.

I am thankful to the non-teaching staff of Holy Cross College of Nursing for their supports and prayers.

I wish to express my gratitude to all my friends Sr.Helen, Sr. Siji, Sr.Sincy and Miss Neeraja.

I am indebted to all those who have directly and indireclty helped, guided, advised and moulded this piece of work and provided information without which I would never have completed this endour. Their precious time, energy, experience and suggestions were a source of inspiration and sustenance.

Above all I lift my eyes to the heaven, bend my kness and offer my deepest sense of everlasting gratitude to God Almighty. Thank you Lord for everything.

\section{References}

1. Annammma Jacob. Clinical Nursing Procedure Jaypee Publication, $1^{\text {st }}$ edition, 1995, 246-250.

2. Armstronge CW, Mayholl CG et al," Clinical predictors of infection of central venous catheter used for total parental nutrition" infection control Hospital epidemiology 1990;11:71-78.

3. Barbara. "Fundamental of nursing "pearson education publication, $6^{\text {th }}$ edition, 2000, 789-792.

4. Berry, Kohn's. "Operating room technique "mosbey publication, 10 $0^{\text {th }}$ edition, 1999, 254.

5. Brunner Suddarth's. Medical Surgical Nursing, $\left(10^{\text {th }}\right.$ ed.), Philadelphia: Lippincott Williams and Wilkins 2004.

6. Braunwald E. Harrison's Principles of Internal Medicine, (15 ${ }^{\text {th }}$ ed.) New York: McGraw-Hill Medical Publishing Division 2001, 1

7. Carol Taylor. "Fundamental of nursing" Williams publications, $8^{\text {th }}$ edition $2003,748-757$.

8. Diane M Billings. "Lippincott's review NCLEX-R" $8^{\text {th }}$ edition 2003, 232.

9. Evegn fcarce. "A General Text book of nursing" Jaypee brother saunders publications, $2^{\text {nd }}$ edition 2001, 45-46.

10. Joyce M Black. "Medical Surgical Nursing -I" $7^{\text {th }}$ edition, mosby publication LTD Delhi 2007, 2378.

11. Jacab Annammma. "Clinical Nursing procedure: the art of nursing practice" $1^{\text {st }}$ edtion, Jaypee brothers medical publishers, New Delhi 2007, 242.
12. Lewis Medical Surgical Nursing assessment and management of clinical problem" $4^{\text {th }}$ edition, Mosbey publication 2001, 201-209.

13. Lippincott. "The manual of nursing practice" $7^{\text {th }}$ edition, Lippincott publication 2005, 958-969.

14. Linda Anne Silverlri Saunder's $3^{\text {rd }}$ edition" comprehensive review for the NClex-RN" 2003, 346.

15. Luckman, Sorensen. Medical Surgical Nursing, $\left(3^{\text {rd }}\right.$ ed.), Philadelphia: W.B. Saunder's Company 1987.

16. Mahajan "text book prevention and social medicine" $3^{\text {rd }}$ edition, jaypee publication 2003, 213-248.

17. Nahata MC et al. Management of catheter related infections in pediatrics patients 1988.

18. Potter, Perry. Basic nursing essential for practice" $5^{\text {th }}$ edition 2004, 352-92,

19. Mary E Braine, Amanda Woodall. A comparison between intravenous and subcutaneous immunogobulin, British Journal of Nursing 2012;21(8) 21-27.

20. Lisa Dougherty. I.V. therapy: get it right no right no matter what, British Journal of Nursing 2012;21(14):310.

21. Nancy Moureau. Safe patient Care when using vascular access devices, British Journal of Nursing 2013;22(2)14-21.

22. Thais, Santolium et al, The strategic role of the nurse in the selection of I.V. device. British Journal of Nursing 2012;22(8):28-31.

23. Ahlquist. Handling of peripheral intravenous cannulae: effect of evidence based clinical guidelines. Journal of clinical nursing 2006;15:1354-1361.

24. Lanbeck Peter. Perception of risk factor for infusion phlebitis among Swedish nurses: a questionnaire study. Journal of infusion nursing. 2004;27(1):25-30.

25. McMullen Kim L. A retrospective charts review of risk factors for extravasation among neonates receiving peripheral intravascular fluids. Journal of wound, osteotomy and continue nursing 2006;33(2):133-139.

26. Verges Chiannamma. Prevention and Reduction of Pain, Bruise and Hematoma by 'Moist Ice Pack' Application on the Site of Subcutaneous Heparin Injection. Nursing and Midwifery Journal 2006;2(4):139-148.

27. Ahlquist. Handling of peripheral intravenous cannulae: effect of evidence based clinical guidelines. Journal of clinical nursing 2006;15:1354-1361.

28. Lanbeck Peter. Perception of risk factor for infusion phlebitis among Swedish nurses: a questionnaire study. Journal of infusion nursing. 2004;27(1):25-30.

29. Mccullen Kim L. A retrospective charts review of risk factors for extravasation among neonates receiving peripheral intravascular fluids. Journal of wound, osteotomy and continue nursing 2006;33(2):133-139.

30. Vergese Chiannamma. Prevention and Reduction of Pain, Bruise and Hematoma by 'Moist Ice Pack' Application on the Site of Subcutaneous Heparin Injection. Nursing and Midwifery Journal. 2006;2(4):139-148.

31. http://en. Wikipedia.org./wiki/ Intravenous therapy.

32. http:// www. Ncbi.nib.gov/pumped/675333.

33. http:// www.ncbi.nib.got/pubmed/ 345325.

34. http:// pmj.bmj.com/cgi/content/full/ 65/9876/1

35. http:// www.med.monash.edu.au/healthservice.com

36. http://linkinghug.Elsevier.com/retrieve/pii/So12344654 $\mathrm{X}$ 
37. http://www.nursingcenter.com/prodev/ce-article.asp

38. http://medicalchronicles.blogspot.com

39. http:www.news-medical.net/news/

40. http://find-health -articles.com

41. http://www.netwellness.org/healthtopics/anesthesiolog/i . $\mathrm{v}$ complications.cfm

42. http://www3.interscience.wiley.com

43. http://pmj.bmj.com/coi/content/full/54/6578/1

44. http://www.infectioncontroltoday/articles/161feats6.ht $\mathrm{ml}$.

45. http://home.intekom.com/pharm/hmr/thrombop.htmlww w.allnurse.com/infusion.Intravenous/ statistics 